\title{
Mammographic breast density in infertile and parous women
}

\author{
Meggiorini Maria Letizia ${ }^{1 *}$, Vestri Anna Rita ${ }^{3}$, De Stefano Maria Grazia' ${ }^{1}$ Cipolla Valentina², Bellati Filippo1, \\ Maffucci Diana ${ }^{1}$, Nusiner Maria Paola ${ }^{1}$, Aragona Cesare ${ }^{1}$ and De Felice Carlo ${ }^{2}$
}

\begin{abstract}
Background: Mammographic breast density is a useful marker for breast cancer risk, as breast density is considered one of the strongest breast cancer risk factors. The study objective was to evaluate and compare mammographic breast density in infertile and parous women, as infertility may be associated with high breast density and cancer occurrence.

Methods: This study evaluated mammographic breast density using two different systems, BIRADS and Boyd. A selected patient population of 151 women with primary infertility (case group) was compared to 154 parous women who had at least one previous pregnancy (control group). Both groups were premenopausal women aged $\geq 35$.

Results: Evaluation of mammographic features showed that $66.9 \%$ of case group patients and $53.9 \%$ of control group patients were classified BIRADS-3/BIRADS-4; $p<0.05$. Adjusted Odds ratio for the case group in the categories BIRADS-3/ BIRADS-4 was 1.78 (95\% Cl: 1.10-2.89). Using the Boyd classification system, $53.6 \%$ of case group patients and $31.8 \%$ of control group patients were classified E/F; $p<0.05$. Adjusted Odds ratio for case group patients in Boyd categories E/F was 2.05 (95 \% Cl: 1.07-3.93).

Conclusions: Both systems yielded a higher percentage of increased breast density in the case group. Boyd and BIRADS classification systems indicate to what extend breast cancer lesions may be missed on mammography due to masking by dense tissue. Therefore, patients with a high BIRADS or Boyd score should undergo further investigation.
\end{abstract}

Keywords: Breast density, Infertility, Parous women

\section{Background}

Infertility is defined as the failure to conceive after one year of regular unprotected intercourse, and prevalence is approximately $10 \%-15 \%$ in Western countries [1]. The demand for infertility services is steadily increasing, and so is the average age of women undergoing in vitro fertilization (IVF) [2, 3]. Infertility treatments implying medication and interventional procedures may modify the hormonal environment and be cofactors in cellular changes leading to cancer development $[4,5]$. However, few studies are reported on breast cancer risk in infertile women who have undergone IVF treatment [6-8].

The association between breast cancer and infertility has not been consistently studied, but it may be explained by hormonal disorders linked to infertility, a

\footnotetext{
* Correspondence: marialetizia.meggiorini@uniroma1.it

'Department of Gynecologic-Obstetrical and Urologic Sciences, "Sapienza"

University of Rome, Viale del Policlinico, 155, Rome 00161, Italy

Full list of author information is available at the end of the article
}

different reproductive risk factor profile in infertile women, or by a combination of these two factors.

Two decades ago, Sellers et al. reported a significantly higher risk of developing breast cancer in nulliparous married women who tried and failed to become pregnant [9]. Weiss et al. [10] found that among women with a first full-term delivery at the age of 35 or older, fertility problems were associated with a two-fold increased risk of breast cancer. In contrast, Venn et al. [5] and Klip et al. [8] summarized the association between infertility and breast cancer and concluded that infertile women did not appear to be at higher risk for breast cancer. However, the possible influence of infertility itself on the risk of breast cancer occurrence should be taken into consideration [11].

The Italian National Federation for Breast Cancer (FONCAM) guidelines 2005 recommend mammography starting at 35 years in women who undergo hormone therapy [12]. 
At the Breast Unit of our institution (Policlinico Umberto I, Rome), all women undergoing fertility treatment are submitted to breast examination, and mammography is performed according to the FONCAM recommendations for women aged $\geq 35$.

Mammographic breast density reflects the relative proportion of glandular and stromal tissue to fatty tissue in the breast. High breast density has been strongly associated with increased risk of breast cancer [13-15], and this parameter could thus be a useful marker for breast cancer risk and be considered one of the strongest risk factors for breast cancer [15]. Breast density is often associated with reproductive and menstrual factors including serum estrogen and progesterone concentrations [16]. Furthermore, breast density is inversely correlated with the accuracy of mammography and therefore a measurement of density conveys information on the difficulty of detecting cancer in a mammogram.

In a previous study, we found that $68 \%$ of women with primary infertility had dense breast tissue according to the BIRADS score compared with $37 \%$ of premenopausal women in a general population [17].

In the present study, two different systems, BIRADS and Boyd, were employed to evaluate mammographic breast density in two selected groups: a case group consisting of infertile women and a control group consisting of parous women. The results obtained in the two groups were subsequently compared.

\section{Methods}

This study was carried out from January 2007 to November 2009. Data collection methods and study design were approved by the institutional review board of the University of Rome "Sapienza" and all patients signed an informed consent form. The study included women with primary infertility referred to our Breast Unit at the Department of Gynaecology and Obstetrics, University of Rome "Sapienza" as well as a control group selected from the database of the Department of Radiology.

A total of 440 patients were referred to our Breast Unit from the IVF Centre for a clinical breast examination before undergoing specific infertility treatment. Of these patients, $51 \%$ were $>35$ years old, $37 \%$ had previously undergone fertility drug treatment and $9 \%$ had secondary infertility. Of the 440 patients, 151 (34\%) were women aged $>35$ with primary infertility who had never undergone fertility drug treatment (case group). The case group was compared to a control group consisting of 154 parous women selected from the database of the Department of Radiology who had at least one previous pregnancy (average 1.3 children per woman). The control group patients had undergone mammography examination for other reasons, such as family history or clinical suspicion of breast tumours, and they were negative for cancer. The age range of the control group was chosen in accordance with the case group: premenopausal women age $\geq 35$. The information collected in both groups included: age, family history of breast cancer with at least 2 first degree relatives, previous administration of hormonal contraceptive therapy (HCT), age at menarche, previous pregnancy or etiology of infertility (if known) as well as height and weight for the calculation of body mass index (BMI). According to the FONCAM recommendations, all recruited case group patients underwent clinical examination and Xray mammography (XRM) after signing the informed consent form. In all cases, conventional XRM was performed at our Department of Radiological Science using digital image formation and computed radiography. At least two views per breast were obtained.

All mammograms were classified using BIRADS and Boyd scales. Classification was carried out by three physicians (two radiologists and a breast specialist) blinded to the clinical data in accordance with the guidelines of the American College of Radiology (ACR) BIRADS. Diagnostic quality of the mammograms was assessed according to the PGMI evaluation system that includes four image quality categories: P (perfect), G (good), M (moderate) and I (inadequate).

BIRADS is a qualitative system, but the recently modified, more quantitative version was employed [18].

According to the BIRADS lexicon, patients were assigned to one of the four categories of breast parenchymal density distribution: BIRADS-1: the breast is almost entirely fat (glandular parenchyma $<25 \%$ of the total area of both breasts); BIRADS-2: scattered fibroglandular densities (25 \%-50 \%); BIRADS-3: heterogeneously dense breast tissue (51 \%-75\%); BIRADS-4: extremely dense (>75 \% glandular tissue). The Boyd scale is based on a visual estimation of the proportion of mammographic density in the projected area, divided into six categories of unequal intervals: type A: $0 \%$; type B: $0-10 \%$; type C:10-25 \%; type D: $25-50 \%$; type E: $50-75 \%$ and type $\mathrm{F}:>75 \%$. In case of contradictory judgments, the classification assigned by at least two readers out of three was considered correct.

Patients were excluded from the study if mammography revealed focal disease, and/or if further diagnostic tests such as breast ultrasound, breast magnetic resonance or needle biopsy were required. To assess whether classification as Dense Breast (DB) and Non Dense Breast (NDB) was consistent, agreement between the three referents was tested using Cohen's kappa before further statistical analysis. It was decided to divide BIRADS into two categories and BOYD into three categories because absolute frequencies for certain categories were very small and this would create problems in the multivariate analysis. 
The sample of 151 women in the case group and 154 in the control group were evaluated as having a $80 \%$ power to detect an OR (Odds Ratio) of 2 at a 0.05 significance level for an exposure (dense breast according to BIRADS score) expected the control group equal to $40 \%$. The proportional odds were tested using the Brant test. For both groups of cases, the proportional odds assumption was verified (chi square $=2.316 p=0.678$ in the case group; chi square $=4.106 p=0.392$ in the control group).

Continuous variables were presented as mean \pm Standard Deviation (SD), and differences were evaluated by the Student's $t$ test or the Mann-Whitney test. Categorical variables were expressed as count and percentages. To assess the association the chi-square test or Fisher's exact test were used as appropriate. Multivariate analyses (ordered logistic regression and binary logistic regression) were used to calculate ORs, including interacting or confounding effects of age, BMI, family history and age at menarche. All tests were two-tailed, and $p$-value $<0.05$ was considered significant. All computations were carried out using STATA v.12.

\section{Results}

Mean age of the 151 case group patients was $38.96 \pm 2.88$ and mean BMI was $23.15 \pm 3.88$. All were affected by primary infertility: $57.8 \%$ sine causa, $37 \%$ ovulatory factors and $5.2 \%$ endometriosis. Of this group, $6.6 \%$ had a positive family history of breast cancer and $40.4 \%$ had received hormonal contraceptive therapy (HCT). Mean age at menarche was $12.34 \pm 1.49$.

Mean age of the 154 control group patients was $41.79 \pm 3.09$ and mean BMI was $22.58 \pm 3.05$. Of this group $52 \%$ had a positive family history of breast cancer and $44.2 \%$ had received contraceptive therapy. Mean age at menarche was $12.44 \pm 1.47$.

The mean age difference between the two groups was statistically significant, but difference in BMI values was not statistically significant (Table 1 ).

All mammograms included in the study were classified as P (perfect) or G (good) according to the PGMI evaluation system.

Table 1 Characteristics of the two study groups

\begin{tabular}{llll}
\hline & $\begin{array}{l}\text { Case group } \\
\text { (151 women) }\end{array}$ & $\begin{array}{l}\text { Control group } \\
(154 \text { women })\end{array}$ & $p$ \\
\hline BMl $(\mathrm{kg} / \mathrm{m} 2)($ mean $\pm \mathrm{SD})$ & $23.15 \pm 3.88$ & $22.58 \pm 3.05$ & 0.591 \\
Age $($ mean $\pm \mathrm{SD})$ & $38.96 \pm 2.88$ & $41.79 \pm 3.09$ & $<0.001$ \\
Family history of & $(6.6 \%) 10$ & $(52 \%) 80$ & $<0.0001$ \\
Breast Cancer (\%) No. & & & \\
Previous use of HCT (\%) No. & $(40.4 \%) 61$ & $(44.2 \%) 68$ & 0.308 \\
Age at menarche (mean $\pm \mathrm{SD})$ & $12.34 \pm 1.49$ & $12.44 \pm 1.47$ & 0.148 \\
\hline
\end{tabular}

Evaluation of mammographic features showed that $33.1 \%(50 / 151)$ of case group patients and $46.1 \%(71 / 154)$ of control group patients were classified BIRADS-1/BIRADS-2; $p<0.05$, and that $66.9 \%(101 / 151)$ of case group patients and $53.9 \%(83 / 154)$ of control group patients were classified BIRADS-3/BIRADS-4; $p<0.05$ (Table 2). Adjusted OR for the case group vs. the control group in categories BIRADS-3/BIRADS-4 was 1.78 (95\% CI: 1.10-2.89); $p=0.02$ (Table 3).

Boyd classification of mammographic features showed that $19.2 \%(29 / 151)$ of case group patients and $22.7 \%$ $(35 / 154)$ of control group patients were assigned to categories A and B ( $p>0.05) ; 27.2 \%(41 / 151)$ of case group patients and $45.5 \%(70 / 154)$ of control group patients were assigned to categories $\mathrm{C}$ and $\mathrm{D}(p<0.05) ; 53.6 \%$ $(81 / 151)$ of case group patients and $31.8 \%(49 / 154)$ of control group patients were assigned to categories $\mathrm{E}$ and F; $(p<0.05)$ (Table 2).

Adjusted OR for the case group vs. the control group in Boyd categories E and F was 2.05 (95 \% CI: 1.07-3.93) $(p=0.03)$. Adjusted OR for categories C and D vs. categories A and B was 0.75 (95 \% CI:0.39-1.46) $(p=0.39)$ (Table 4).

\section{Discussion}

Breast cancer is the most common malignancy in women and a leading cause of cancer-related death worldwide $[15,19]$. In the absence of a known preventable cause of breast cancer, the single most important factor in reducing mortality is early detection. Mammography and ultrasound are currently the techniques of choice for breast cancer evaluation. The sensitivity of mammography varies and is influenced by breast density. Dense fibroglandular tissue is the most important inherent limitation of mammography in the diagnosis of breast cancer [12], and dense breast tissue is considered a risk factor in the subsequent development of breast cancer [19].

Mammographic breast density is very often linked to cancer due to masking bias, as malignant lesions have the same $\mathrm{x}$-ray attenuation properties as fibroglandular tissue $[19,20]$. In our previous study, we analysed a selected population of women with primary infertility and

Table 2 Evaluation of mammographic features using the BIRADS and Boyd systems

\begin{tabular}{llll}
\hline & $\begin{array}{l}\text { Case group } \\
(151 \text { women })\end{array}$ & $\begin{array}{l}\text { Control group } \\
(154 \text { women })\end{array}$ & $p$ \\
\hline BIRADS-1/BIRADS-2 & $33.1 \%$ & $46.1 \%$ & 0.026 \\
BIRADS-3/BIRADS-4 & $66.9 \%$ & $53.9 \%$ & 0.026 \\
Boyd Cat. A/B & $19.2 \%$ & $22.7 \%$ & $\mathrm{NS}$ \\
Boyd Cat. C/D & $27.2 \%$ & $45.5 \%$ & $<0.0001$ \\
Boyd Cat. E/F & $53.6 \%$ & $31.8 \%$ & $<0.0001$ \\
\hline
\end{tabular}


Table 3 Odds ratios, $95 \%$ confidence intervals and $p$-values for higher BIRADS categories (BIRADS 3/4) for characteristics of the study population (Odds ratio for each variable is adjusted for the remaining variables shown in the table)

\begin{tabular}{lllcl}
\hline BIRADS Cat. 1/2 & OR & \multicolumn{2}{l}{$\begin{array}{l}\text { Confidence interval 95 \% } \\
\text { lower bound upper bound }\end{array}$} & $p$ value \\
\hline Family history & 1.32 & 0.59 & 2.95 & 0.50 \\
Age at menarche & 0.86 & 0.69 & 1.06 & 0.15 \\
BMI normal & 1.52 & 0.46 & 5.03 & 0.49 \\
BMl overweight & 0.50 & 0.13 & 1.86 & 0.30 \\
BMI obese & 0.45 & 0.10 & 2.06 & 0.31 \\
Age 35-39 & 3.99 & 1.26 & 12.61 & 0.02 \\
Age $\geq 40$ & 2.46 & 0.77 & 7.91 & 0.13 \\
BIRADS 3/4 & 1.78 & 1.10 & 2.89 & 0.02 \\
\hline
\end{tabular}

we found that $68 \%$ of patients had dense breasts according to the BIRADS score [17]. The study in question presented some limitations: it lacked a control group and used only the BIRADS system, which was originally a morphological assessment.

This is the first study that has investigated breast density of infertile women referred to assisted conception services and compared the outcome with a group of premenopausal parous women aged $\geq 35$. In this study, two methods were used to assess mammographic density, BIRADS and Boyd, and both confirmed previous results for the infertile women. The percentage of dense breasts in the group of women with primary infertility was higher using both BIRADS ( $66.9 \%$ vs. $53.9 \%, p<0.05)$ and Boyd $(53.6 \%$ vs. $31.8 \%, p<0.05)$ compared to parous woman. One of the most important limitations of this study is the difference in the mean age between the two groups. Mean age of the control group was higher, because mammographic screening and other preventive measures before age 40 are not recommended except in women at high risk of breast cancer [12]. According to the FONCAM

Table 4 Odds ratios, $95 \%$ confidence intervals and $P$ values for higher Boyd grades for characteristics of the study population (Odds ratio for each variable is adjusted for the remaining variables shown in the table)

\begin{tabular}{lllcl}
\hline $\begin{array}{l}\text { Boyd Classification } \\
\text { Cat. A/B }\end{array}$ & OR & \multicolumn{2}{l}{$\begin{array}{l}\text { Confidence interval 95 \% } \\
\text { lower bound upper bound }\end{array}$} & $P$ value \\
\hline Family history & 1.06 & 0.46 & 2.47 & 0.89 \\
Age at menarche & 0.96 & 0.79 & 1.18 & 0.72 \\
BMl normal & 1.42 & 0.42 & 4.98 & 0.59 \\
BMl overweight & 0.56 & 0.12 & 1.98 & 0.34 \\
BMl obese & 0.45 & 0.09 & 2.45 & 0.32 \\
Age 35-39 & 3.13 & 1.12 & 9.77 & 0.04 \\
Age $\geq 40$ & 1.45 & 0.83 & 2.52 & 0.20 \\
Boyd Cat. C/D & 0.75 & 0.39 & 1.46 & 0.39 \\
Boyd Cat. E/F & 2.05 & 1.07 & 3.93 & 0.03 \\
\hline
\end{tabular}

guidelines, the first diagnostic approach recommended before age 40 is clinical examination. If suspicious signs for malignancy are found, ultrasound is performed, followed by a mammogram if necessary [12]. Therefore, from the database of the Department of Radiology, we selected women who had undergone mammography examinations for various reasons. This caused a slight difference between the mean age in the two study groups. Sensitivity and specificity of mammographic evaluation is lower in younger women than in older women because younger woman more often have dense breast tissue [21]. Therefore, we used multivariate analysis to take into account potential confounding factors, such as age, BMI and family history. Nevertheless, dense breast tissue was more frequent in the case group as established according to the Boyd and BIRADS systems. The role of nulliparity as a risk factor for breast density has been discussed in several studies [13, 22]. There might be a biological relationship between parity and the risk of breast cancer given that high breast density is present in most nulliparous women $[10,14,17]$. Furthermore, nulliparous women often present a large quantity of undifferentiated epithelial breast tissue, which is more susceptible to carcinogenetic stimuli such as endogenous and exogenous female hormones [23].

\section{Conclusions}

In conclusion, this study confirms that patients with primary infertility have denser breast tissue and may be at risk for breast cancer.

The Boyd and BIRADS systems were not developed to quantify the risk, but to allow an interpreting radiologist to indicate the level of concern that a cancer lesion in the breast might be missed on mammography due to masking by dense tissue.

Infertile women with high BIRADS or Boyd scores, who undertake IVF treatment, should be investigated with appropriate diagnostic tools including magnetic resonance imaging (MRI) to reduce masking bias.

\section{Abbreviations}

BIRADS: Breast imaging-reporting and data system; IVF: In vitro fertilization; F.O.N.Ca.M.: Forza operativa nazionale sul carcinoma mammario; HCT: Hormonal contraceptive therapy; BMI: Body mass Index; XRM: X-Ray mammography; ACR: American college of radiology; DB: Dense breast; NDB: Non dense breast; OR: Odds ratio.

Competing interests

The authors declare that they have no competing interests.

Authors' contributions

All authors have substantially contributed to the conception of this study and the drafting of the article, and all have approved the final version of the paper. MML and DSMG collected the data of patients at the Breast Center with the help of NMP, BF and MD. The infertile patients were selected at the IVF center of IVF by AC. Radiological examination was performed by DFC and $\mathrm{CV}$. The statistical method for the allocation of groups and for the data processing was followed by VAR. 


\section{Acknowledgements}

We thank Karen Outtrup for the English revision of the manuscript.

\section{Author details}

'Department of Gynecologic-Obstetrical and Urologic Sciences, "Sapienza" University of Rome, Viale del Policlinico, 155, Rome 00161, Italy. ${ }^{2}$ Department of Radiological Sciences, "Sapienza" University of Rome, Viale del Policlinico, 155, Rome 00161, Italy. ${ }^{3}$ Department of Public Health and Infectious Diseases, "Sapienza" University of Rome, Viale del Policlinico, 155, Rome 00161, Italy.

Received: 8 June 2014 Accepted: 20 January 2016

Published online: 09 February 2016

\section{References}

1. Crosignani PG, Rubin B. The ESHRE Capro Workshop. Guidelines to the prevalence, diagnosis, treatment and management of infertility. Hum Reprod. 1996;11:1775

2. Stephen E, Chandra A. Updated projections of infertility in the United States: 1995-2025. Fertil Steril. 1998;70(1):30-4.

3. Nyboe Andersen A, Goosens V, Bhattacharya S, Ferraretti AP, Kupka MS, de Mouzon J, et al. The European IVF monitoring (EIM) Consortium for the European Society of Human Reproduction and Embryology (ESHRE), Assisted reproductive technology and intrauterine inseminations in Europe, 2005: results generated from European registers by ESHRE. Human Reproduction. 2009;24(6):1267-87.

4. Modan B, Ron E, Lerner-Geva L, Blumstein T, Menczer J, Rabinovici J, et al Cancer incidence in a cohort of infertile women. Am J Epidemiol. 1998; 147(11):1038-42.

5. Venn A, Watson L, Bruinsma F, Giles G, Healy D. Risk of cancer after use of fertility drugs with in vitro fertilization. Lancet. 1999;354(9190):1586-90

6. Ron E, Lunenfeld B, Menczer J, Blumstein T, Katz L, Oelsner G, et al. Cancer incidence in a cohort of infertile women. Am J Epidemiol. 1987;125(5):780-90.

7. Venn A, Watson L, Lumley J, Giles G, King C, Healy D. Breast and ovarian cancer incidence after infertility and in vitro fertilisation. Lancet. 1995:346(8981):995-1000.

8. Klip H, Burger CW, Kenemans P, Van Leeuwen FE. Cancer risk associated with subfertility and ovulation induction: a review. Cancer Causes Control. 2000;11(4):319-44.

9. Sellers TA, Potter JD, Severson RK, Bistick RM, Nelson CL, Kushi LH, et al. Difficulty becoming pregnant and family history as interactive risk factors for postmenopausal breast cancer: the lowa Women's Health Study. Cancer Causes Control. 1993;4(1):21-8.

10. Weiss HA, Troisi R, Rossing MA, Brogan D, Coates RJ, Gammon MD, et al. Fertility problems and breast cancer risk in young women: a case-control study in the United States. Cancer Control. 1998;9(3):331-9.

11. Pappo I, Lerner-Geva L, Halevy A, Olmer L, Friedler S, Raziel A, et al. The possible association between IVF and breast cancer incidence. Ann Surg Oncol. 2008;15(4):1048-55.

12. FONCAM Guidelines. 2005. Available: http://www.senologia.it/images/pdf/ diagnostica\%20in\%20senologia.pdf.

13. Wolfe JN. Breast patterns as an index of risk for developing breast cancer. Am J Roentgenol. 1976;126(6):1130-7.

14. Wolfe JN. Risk for breast cancer development determined by mammographic parenchymal pattern. Cancer. 1976;37(5):2486-92.

15. Boyd NF, Lockwood GA, Byng JW, Tritchler DL, Yaffe MJ. Mammographic densities and breast cancer risk. Cancer Epidemiol Biomarkers Prev. 1998;7(12):1133-44.

16. Martin LJ, Boyd N. Potential mechanisms of breast cancer risk associated with mammographic density: hypotheses based on epidemiological evidence. Breast cancer Res. 2008;10(1):201.

17. Meggiorini ML, Cipolla V, Rech F, Labi L, Vestri A, de Felice C. Mammographic features in infertile women as a potential risk for breast cancer: a preliminary study. Eur J Gynaecol Oncol. 2012;33(1):51-5.

18. Yaffe MJ. Mammographic density. Measurement of mammographic density. Breast Cancer Research. 2008;10(3):209.

19. Kolb TM, Lichy J, Newhouse JH. Comparison of the performance of screening mammography, physical examination, and breast us and evaluation of factors that influence them: an analysis of 27825 patient evaluations. Radiology. 2002;225(1):165-75.
20. Agashe PP, Shrikhande SV. Genetics of breast cancer for the practicing surgeon. http://www.bhj.org.in/journal/2001_4304_oct/review_537.htm. Accessed June 12th, 2013.

21. Speroff $L$. The effect of aging on fertility. Curr Opin Obstet Gynecol. 1994;6(2):115-20.

22. De Waard F, Rombach JJ, Collette HJA, Slotboom B. Breast cancer risk associated with reproductive factors and breast parenchymal patterns. J Natl Cancer Inst. 1984;72(6):1277-82.

23. Morimoto Y, Killeen J, Hernandez BY, Cline JM, Maskarinec G. Parity and expression of epithelial histopathologic markers in breast tissue. Eur J Cancer Prev. 2013:22(5):404-8.

\section{Submit your next manuscript to BioMed Central and we will help you at every step:}

- We accept pre-submission inquiries

- Our selector tool helps you to find the most relevant journal

- We provide round the clock customer support

- Convenient online submission

- Thorough peer review

- Inclusion in PubMed and all major indexing services

- Maximum visibility for your research

Submit your manuscript at www.biomedcentral.com/submit 